\title{
Drought Assessment by a Short-/Long-Term Composited Drought Index in the Upper Huaihe River Basin, China
}

\author{
Meixiu Yu, ${ }^{1,2,3}$ Xiaolong Liu, ${ }^{3}$ Li Wei, ${ }^{4}$ Qiongfang Li, ${ }^{1,2}$ \\ Jianyun Zhang, ${ }^{3}$ and Guoqing Wang ${ }^{3}$ \\ ${ }^{1}$ College of Hydrology and Water Resources, Hohai University, Nanjing 210098, China \\ ${ }^{2}$ Center for International River Research, School of Business, Hohai University, Nanjing 210098, China \\ ${ }^{3}$ Hydrology and Water Resources Department, Nanjing Hydraulic Research Institute, Nanjing 210024, China \\ ${ }^{4}$ Hydrology Bureau of Jiangxi Province, Nanchang 332000, China
}

Correspondence should be addressed to Meixiu Yu; meixiuyu1985@gmail.com and Qiongfang Li; li_qiongfang@hotmail.com

Received 29 May 2015; Accepted 4 October 2015

Academic Editor: Mohsin Hafeez

Copyright (C) 2016 Meixiu Yu et al. This is an open access article distributed under the Creative Commons Attribution License, which permits unrestricted use, distribution, and reproduction in any medium, provided the original work is properly cited.

\begin{abstract}
Accurate and reliable drought monitoring is of primary importance for drought mitigation and reduction of social-ecological vulnerability. The aim of the paper was to propose a multiscale composited drought index (CDI) which could be widely used for drought monitoring and early warning in China. In the study, the upper Huaihe River basin above the Xixian gauge station, which has been hit by severe droughts frequently in recent decades, was selected as the case study site. The newly built shortterm/long-term CDI comprehensively considered three natural forms of drought (meteorological, hydrological, and agricultural) by selection of different variables that are related to each drought type. The short-term/long-term CDI was developed using the Principle Component Analysis of related drought components. The thresholds of the short-term/long-term CDI were determined according to frequency statistics of different drought indices. Finally, the feasibility of the two CDI was investigated against the self-calibrating Palmer drought severity index, the standardized precipitation evapotranspiration index, and the historical drought records. The results revealed that the short-term/long-term CDI could capture the onset, severity, and persistence of drought events very well with the former being better at identifying the dynamic evolution of drought condition and the latter better at judging the changing trend of drought over a long time period.
\end{abstract}

\section{Introduction}

Drought is one of the most damaging natural hazards and often results in devastating effects to social and ecological systems (Hao and Aghakouchak, [1]). The annual economic damage of severe droughts across China is estimated to be 2.5-3.5 percent of the gross domestic product. The frequency of severe and extreme droughts in China increased significantly from 26.8 percent during $1950-1990$ to 47.6 percent during 1991-2011 [2], and the drought percentage area increased by 3.92 percent/10a from 1990s (Yu et al., [3]). Thus, accurate and reliable drought monitoring and prediction are of critical importance for risk assessment and decision making. Different drought indices have been developed and applied for drought monitoring and assessment.
The Palmer drought severity index (PDSI; Palmer [4]) and self-calibrating PDSI (scPDSI; Wells et al. [5]) are widely used for drought characterization. The standardized precipitation index (SPI; McKee et al. [6]) and the standardized precipitation evapotranspiration index (SPEI; Vicente-Serrano et al., [7]) are commonly used for meteorological drought monitoring. The standardization concept was also applied to other drought indices such as the standardized soil moisture index (SMI) and the standardized streamflow index (SSI, Vicente-Serrano et al., [8]). However, the performance of different drought index differs in detecting the drought onset, persistence, and termination. Wilhite [9] concluded that using a single index to reveal the diversity and complexity of drought conditions and impact is one of the major limitations to drought monitoring. Due to the fact that no single index 
can represent all aspects of meteorological, agricultural, and hydrological droughts, a multi-index approach should be proposed for drought monitoring, assessment, and prediction (Hao and Aghakouchak, [1]). Located in a transition zone between the climates of North and South China, the Huaihe River basin was determined to be the region being easily hit by floods and droughts frequently. Xie et al. [10] investigated the feasibility of six drought indices (Rainfall Anomaly Index (RAI), Z index, SPI index, Relative Moisture Index, Composited Meteorological Index (CMI), and modified CMI) in the Huaihe River basin during 1961-2010 and concluded that the CMI and the modified CMI were better at identifying drought events. Zhang et al. [11] assessed the drought condition of the upper Huaihe River basin by the PDSI and the RAI, and the result revealed that the RAI was much more sensitive than the PDSI in drought monitoring. Zhang et al. [12] analyzed the evolution of hydrological drought features under the regulation of two cascade reservoirs in the Huaihe River of China and indicated that although the downstream reservoir leads to an overall increase in the drought severity, it mitigates the severe and extreme droughts; the reservoir storage functions to smooth streamflow variation in that it reduces the drought frequency and extends the duration. Admittedly, the drought assessment and monitoring in the Huaihe River basin have been a focus of many meteorologists and hydrologists (Zhang et al., [13]; Cai et al., [14]; Wang et al., [15]; Duan et al., [16]; Yan et al., [17]). However, previous research on drought in the study area is mostly based on one single drought index or only considered one type of drought. The aim of this paper is to introduce and evaluate a shortterm/long-term composited drought index (S_CDI/L_CDI) which comprehensively considered three natural forms of drought (meteorological, hydrological, and agricultural) by selection of different variables that are related to each drought type in the upper Huaihe River basin. The output of the study could provide valuable references for the drought monitoring and early warning system development in the Huaihe River basin and other regions/basins in China.

\section{Short-/Long-Term CDI Development}

2.1. Selection of CDI Components. Based on the differences in time scales and drought types of drought index, the scPDSI, the 1- and 3-month SPEI, ZIND, and the SMI were selected to develop the short-term CDI by using the Principle Component Analysis (PCA), while the Palmer Hydrology Drought Index (PHDI), the 6-, 12-, 18-, and 24-month SPEI, the SSI, and the SMI were chosen to formulate the long-term CDI. The dynamic evolution of drought condition can be obtained by the short-term CDI while the changing trend of drought over a long time period could be known by the longterm CDI.

2.2. Principle Component Analysis. The PCA method is a technique applied to multivariate analysis for dimensionality reduction [18]. The original intercorrelated variables could be reduced to a small number of new linearly uncorrelated ones that explain most of the total variance.
Considering $k$ variables in a given time period $i, X_{i, 1}$, $X_{i, 2}, \ldots, X_{i, k}, k$ principle components (PCs) are produced for the same time period, $Y_{i, 1}, Y_{i, 2}, \ldots, Y_{i, k}$, using linear combinations of the first ones, according to

$$
\begin{gathered}
Y_{i, 1}=e_{11} X_{i, 1}+e_{12} X_{i, 2}+\cdots+e_{1 k} X_{i, k} \\
Y_{i, 2}=e_{21} X_{i, 1}+e_{22} X_{i, 2}+\cdots+e_{2 k} X_{i, k} \\
\vdots \\
Y_{i, k}=e_{k 1} X_{i, 1}+e_{k 2} X_{i, 2}+\cdots+e_{k k} X_{i, k} .
\end{gathered}
$$

In the applications the variables $X_{i, k}$ refer to scPDSI, SPEI1, SPEI3, ZIND, SMI, and series for short-term CDI, and refer to PHDI, SPEI6, SPEI12, SPEI18, SPEI24, SSI, and SMI series for long-term CDI. $k$ is equal to the number of drought indices ( 5 for short-term CDI and 7 for long-term CDI) and $i$ represents the length of drought indices series.

In (1) $Y_{i, 1}$ explains most of the variance, $Y_{i, 2}$ explains the reminiscent amount of variance, and so on. PCs extraction could be based on variance/covariance or correlation matrix of data with $\left\{e_{11}, e_{21}, \ldots, e_{1 k}\right\}$ being the first eigenvector and $\left\{e_{11}, e_{21}, \ldots, e_{1 k}\right\}$ being the eigenvector of $k$ order and each eigenvector includes the coefficients of the $k$ principal component. Finally, the amount of variance explained by the first PC is called the first eigenvalue $\lambda_{1}$, and the second is $\lambda_{2}$, so that $\lambda_{1} \geq \lambda_{2} \geq \cdots \geq \lambda_{k}$. Since each eigenvalue represents the fraction of the total variance in the original data and is explained by each component, proportion of each component can be calculated as $\lambda_{j} / \sum \lambda_{j}$. Thus, the short-term/long-term CDI can be expressed as follows:

$$
\begin{aligned}
\mathrm{CDI}_{i}= & \frac{\lambda_{1}}{\lambda_{1}+\lambda_{2}+\cdots+\lambda_{k}} Y_{i, 1}+\cdots \\
& +\frac{\lambda_{j}}{\lambda_{1}+\lambda_{2}+\cdots+\lambda_{k}} Y_{i, j}+\cdots \\
& +\frac{\lambda_{n}}{\lambda_{1}+\lambda_{2}+\cdots+\lambda_{k}} Y_{i, k},
\end{aligned}
$$

where $\lambda_{j}$ is eigenvalue of the $j$ th principal component, $Y_{i, j}$ is the $j$ th principal component of the $i$ th month, $\mathrm{CDI}_{i}$ is the short-term/long-term CDI in the $i$ th month.

2.3. Short-/Long-Term CDI Formulation. According to (1) and (2), the short-term CDI can be formulated as follows:

$$
\begin{aligned}
& \mathrm{S}_{-} \mathrm{CDI}_{i}=\sum_{1}^{k} \frac{\lambda_{j}}{\lambda_{1}+\lambda_{2}+\cdots+\lambda_{k}} X_{\mathrm{S}} E_{\mathrm{S}}, \\
& X_{\mathrm{S}}=\left(x_{\mathrm{SCPDSI}, i}, x_{\mathrm{ZIND}, i}, x_{\mathrm{SPEI}, i}, x_{\mathrm{SPEI} 3, i}, x_{\mathrm{SMI}, i}\right) ; \\
& E_{\mathrm{S}}=\left(e_{\mathrm{SCPDSI}, i, j}, e_{\mathrm{ZIND}, i, j}, e_{\mathrm{SPEI} 1, i, j}, e_{\mathrm{SPEI}, i, j}, e_{\mathrm{SMI}, i, j}\right)^{T} .
\end{aligned}
$$


And the long-term CDI can be formulated as follows:

$$
\begin{aligned}
& \mathrm{L} \_C D I_{i}=\sum_{1}^{k} \frac{\lambda_{j}}{\lambda_{1}+\lambda_{2}+\cdots+\lambda_{k}} X_{\mathrm{L}} E_{\mathrm{L}}, \\
& X_{\mathrm{L}}=\left(x_{\mathrm{SMI}, i}, x_{\mathrm{PHDI}, i}, x_{\mathrm{SSI}, i}, x_{\mathrm{SPEI}, i, i}, x_{\mathrm{SPEI} 12, i}, x_{\mathrm{SPEI} 18, i},\right. \\
& \left.\quad x_{\mathrm{SPEI} 24, i}\right) ; \\
& E_{\mathrm{L}}=\left(e_{\mathrm{SMI}, i, j}, e_{\mathrm{PHDI}, i, j}, e_{\mathrm{SSI}, i, j}, e_{\mathrm{SPEI} 6, i, j}, e_{\mathrm{SPEI} 12, i, j}, e_{\mathrm{SPEI} 18, i, j},\right. \\
& \left.\quad e_{\mathrm{SPEI} 24, i, j}\right)^{T},
\end{aligned}
$$

where $\lambda_{j}$ are eigenvalues of the $j$ th principal component, $e_{i, j}$ are eigenvectors of the $j$ th principal component of the $i$ th month, $X_{i}$ is the drought index series in the $i$ th month, S_CDI and $\mathrm{L}_{-} \mathrm{CDI}_{i}$ are the short-term CDI and the long-term CDI in the $i$ th month.

It should be noted that the monthly scPDSI, ZIND, PHDI, and SPEI (in time scales of 1-month, 3-month, 6-month, 12month, 18-month, and 24-month, resp.) could be obtained based on the daily air temperature and precipitation from meteorological stations in/around the study basin, while the monthly SMI and the SSI need to be calculated by soil water volume and generated runoff based on the hydrological modelling. The gridded Xinanjiang model (XAJ; Zhao, [19]), a model of runoff formation on saturation of storage, used widely in humid and semi-humid regions in China, was adopted to simulate the gridded soil water and generated runoff in the upper Huaihe River basin.

2.4. XAJ Model. The XAJ model is a rainfall-runoff, distributed, basin model for use in humid and semi-humid regions. The evapotranspiration component is represented by a model of three soil layers. Runoff production occurs on repletion of storage to capacity values which are assumed to be distributed throughout the basin. Prior to 1980, runoff was separated into surface and groundwater components using Horton's concept of infiltration. Subsequently, the concept of hillslope hydrology was introduced with an additional component, interflow, being identified. Runoff concentration to the outflow of each subbasin is represented by a unit hydrograph or by a lag and route technique. The damping or routing effects of the channel system connecting the subbasins are represented by Muskingum routing. There are fifteen parameters in all, of which the model is particularly sensitive to six. Optimization of the parameters is achieved with different objective functions according to the nature of each parameter. The model has been widely used in China since 1980, mainly for flood forecasting, though more recently it is also being used for other purposes.

2.5. Determination of the Drought Intensity Threshold Levels of the CDI Categories. The drought intensity threshold levels of the short-term CDI were conducted as in the following steps: firstly, calculate the drought event frequency $F_{i, j}$ ( $i$ for the drought intensity level, $j$ for different drought index) of all

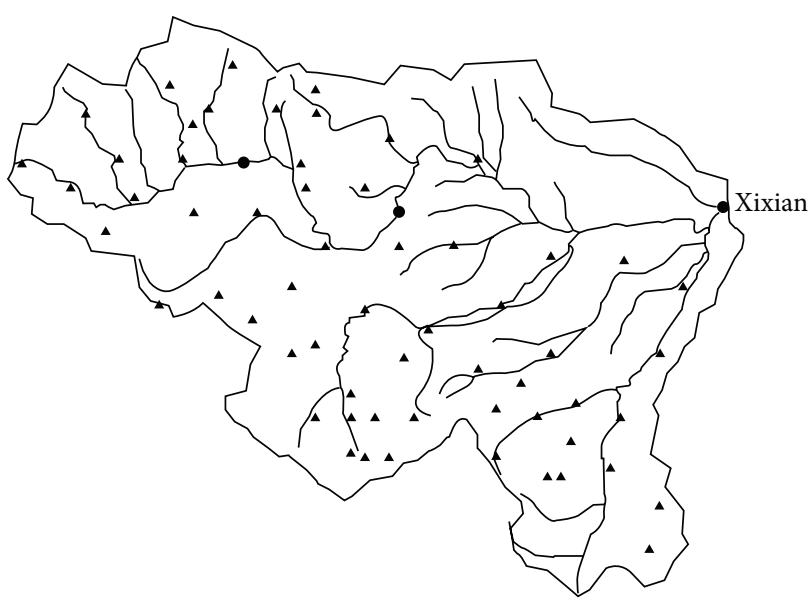

- Hydrological station

- Rainfall station - River net

$\square$ Basin boundary

FIGURE 1: Sketch map of the upper Huaihe River basin.

the short-term drought components with different drought intensity level in the upper Huaihe River basin above the Xixian station; secondly, average $F_{i, j}$ for the same drought intensity level, and then a series of new drought frequencies $f_{i}$ ( $i$ for the drought intensity level) of different drought intensity levels for the short-term CDI was obtained; thirdly, determine the drought intensity threshold levels of the short-term CDI according to $f_{i}$. The drought intensity threshold levels of the long-term CDI can also be acquired by following the above steps.

\section{Application of the Short-/Long-Term CDI}

3.1. Case Study Site. The Huaihe River basin is one of seven major river basins in China and lies in the warm temperature semi-humid monsoon region, which is a transition zone between the climates of North and South China. Special geographical location determined that the Huaihe River basin was a region easily hit by floods and droughts over many centuries, particularly in recent decades, and severe droughts occurred much more frequently which caused huge economic and social loss. To propose a short-/long-term CDI which could be widely used for drought monitoring and early warning in China, this paper selected the upper Huaihe River basin above Xixian gauge station as the case study site with a catchment area of $10190 \mathrm{~km}^{2}$ (see Figure 1).

3.2. Data Preparation and Processing. Considering the spatial unevenness of underlying conditions and meteorological variables, the study areas were divided into grids with a size of $1 \mathrm{~km} \times 1 \mathrm{~km}$. Based on the daily observed meteorological variables (precipitation and air temperature) from closer six meteorological stations during 1988-2005, the inverse distance-squared weighted method was used to acquire the meteorological data for every grid. Before the interpolation, 
TABLE 1: Calibrated parameters for the daily Xinanjiang model in upper Huaihe River above the Xixian station.

\begin{tabular}{llc}
\hline Parameters & Meaning & \\
\hline KC & Ratio of potential evapotranspiration to pan evaporation & Values \\
UM & Areal mean tension water capacity in the upper layer $(\mathrm{mm})$ & 0.89 \\
LM & Areal mean tension water capacity in the lower layer $(\mathrm{mm})$ & 28 \\
$c$ & Coefficient of deep evapotranspiration & 85 \\
\hline WM & Areal mean tension water capacity $(\mathrm{mm})$ & 0.167 \\
$b$ & Exponent of the tension water capacity curve & 150 \\
IM & Ratio of the impervious to the total area of the basin & 0.45 \\
SM & Areal mean of the free water capacity of the surface soil layer $(\mathrm{mm})$ & 0.001 \\
EX & Exponent of the free water capacity curve \\
KG & Outflow coefficient of the free water storage to groundwater relationship \\
\hline CS & Recession constant of surface water storage & 15 \\
CI & Recession constant of interflow water storage \\
CG & Recession constant of groundwater storage & 0.55 \\
$L$ & Lag time (d) & 0.62 \\
KE & Parameter of the Muskingum method \\
XE & Parameter of the Muskingum method & 0.85 \\
\hline
\end{tabular}

digital elevation model was used to correct the meteorological variables according to meteorological variable-elevation relationships. Monthly gridded scPDSI, ZIND, PHDI, and SPEI (1-month, 3-month, 6-month, 12-month, 18-month, and 24-month, resp.) was calculated on the basis of the gridded meteorological variables, and then the monthly areal drought indices were obtained by averaging their gridded values.

3.3. Application of the XAJ Model. Based on the topography, hydrological, and meteorological data in 1988-2005, the daily gridded XAJ model was adopted to simulate gridded soil water and generated runoff in the upper Huaihe River basin above Xixian station. The calibration and validation periods were 1988-2002 and 2003-2005, respectively (Tables 1 and 2). The result revealed that the daily XAJ model was simulated with satisfactory accuracy, which indicated that the calculated gridded soil water and generated runoff could be used for the further CDI construction. The monthly gridded SMI and SSI were computed based on the gridded soil water and generated runoff, and then the areal monthly SMI and SSI were carried out by averaging the gridded values. It should be noted that the soil field capacity was obtained from the International Geosphere-Biosphere Programme (IGBP) which provides the gridded Profile Available Water Capacity with the spatial resolution of $10 \mathrm{~km} \times 10 \mathrm{~km}$. Figure 2 showed the temporal variations of the areal averaged soil moisture index in the upper Huaihe River basin.

3.4. Application of the Short-/Long-Term CDI. Based on the time series of areal monthly scPDSI, ZIND, 1-month SPEI, 3month SPEI, and SMI, according to (3), the short-term CDI in the upper Huaihe River basin above the Xixian station was carried out with the SPSS package. The eigenvalues and eigenvectors in (3) can be referred to in Table 3. And the
TABLE 2: Calibration and validation results of the daily XAJ model in the upper Huaihe River basin.

\begin{tabular}{ccccc}
\hline Periods & $\begin{array}{c}P \\
(\mathrm{~mm})\end{array}$ & $\begin{array}{c}R_{o} \\
(\mathrm{~mm})\end{array}$ & $\begin{array}{c}R_{c} \\
(\mathrm{~mm})\end{array}$ & $\begin{array}{c}\mathrm{RE} \\
\%\end{array}$ \\
\hline $\begin{array}{c}\text { Calibration } \\
1988\end{array}$ & 787.6 & 193.8 & 202.2 & 4.3 \\
1989 & 1153 & 475.1 & 457.6 & -2.6 \\
1990 & 877.6 & 295.9 & 284.3 & -3.9 \\
1991 & 1197.7 & 609.8 & 584.6 & -3 \\
1992 & 744.2 & 149.8 & 164.5 & 11.1 \\
1993 & 840.5 & 224.5 & 222.8 & -0.8 \\
1994 & 849.6 & 179.0 & 192.8 & 7.7 \\
1995 & 881.2 & 214.8 & 232.8 & 9.6 \\
1996 & 1141.5 & 521.0 & 508.7 & -1.2 \\
1997 & 782.3 & 226.0 & 221.4 & -2 \\
1998 & 1166.6 & 616.4 & 511.5 & -17 \\
1999 & 573.8 & 80.3 & 86.8 & 8.1 \\
2000 & 1328 & 578.4 & 624.6 & 9.2 \\
2001 & 456.6 & 104.6 & 96.5 & -7.7 \\
2002 & 1108.1 & 348.2 & 411.1 & 19.4 \\
\hline Validation & & & & \\
2003 & 1145.9 & 611.5 & 512.7 & -16.2 \\
2004 & 933.7 & 279.0 & 327.9 & 17.5 \\
2005 & 1253.2 & 601.3 & 608.2 & 1.15 \\
\hline
\end{tabular}

Note: $P$ is for precipitation, $R_{o}$ for observed runoff, $R_{c}$ for calculated runoff, and RE for relative error.

drought intensity threshold levels of the short-term CDI were determined according to Section 2.5 (Table 4).

Based on the time series of areal monthly PHDI, 6-month SPEI, 12-month SPEI, 18-month SPEI, 24-month SPEI, SSI, and SMI, according to (4), the long-term CDI in the upper Huaihe River basin above the Xixian station was carried out 
TABLE 3: Eigenvalues and eigenvectors of the PCA for short-term/long-term CDI in the upper Huaihe River basin.

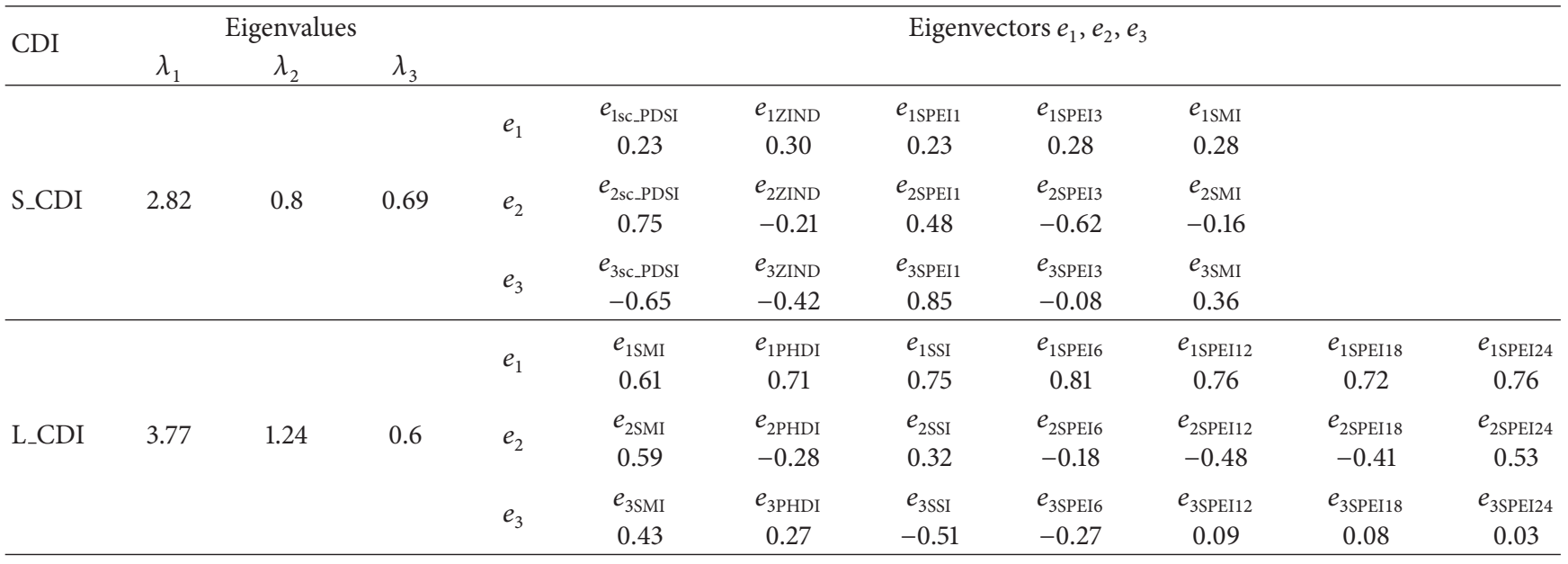

Notes: $\lambda_{1}, \lambda_{2}, \lambda_{3}$ are eigenvalues; $e_{1}, e_{2}, e_{3}$ are eigenvectors.

TABLE 4: Drought categories of the short-term/long-term CDI.

\begin{tabular}{lcc}
\hline Drought category & Short-term CDI & Long-term CDI \\
\hline Normal & $(-0.37,+\infty)$ & $(-0.33,+\infty)$ \\
Mild drought & $(-0.69,-0.37)$ & $(-0.78,-0.33)$ \\
Moderate drought & $(-0.97,-0.69)$ & $(-1.16,-0.78)$ \\
Severe drought & $(-1.36,-0.97)$ & $(-1.39,-1.16)$ \\
Extreme drought & $(-\infty,-1.36)$ & $(-\infty,-1.39)$ \\
\hline
\end{tabular}

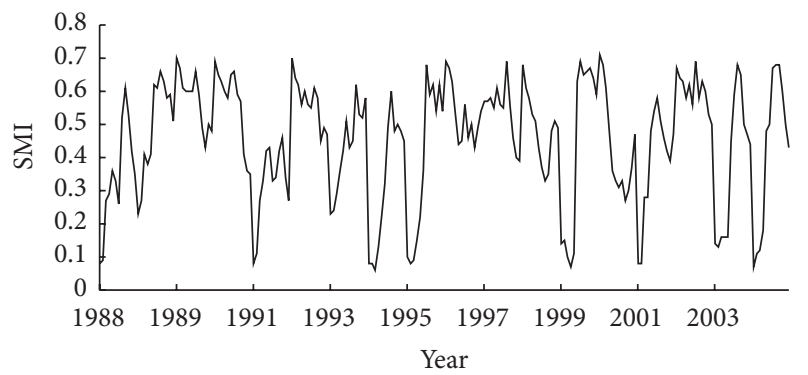

FIGURE 2: Temporal variations of the SMI in the upper Huaihe River basin.

with the SPSS package. The eigenvalues and eigenvectors in (4) can be referred to in Table 3. And the drought intensity threshold levels of the long-term CDI were determined according to Section 2.5 (Table 4).

\section{Results and Discussion}

4.1. Temporal Variations of the Short-Term/Long-Term CDI and Other Drought Indices. The chronological comparison between the S_CDI and the scPDSI and the S_CDI and the 1-month SPEI time series in the upper Huaihe River basin above Xixian station during 1988-2005 was displayed in Figure 3. It has been found that the three drought indices identified most dry conditions of the upper Huaihe River basin: the drier the conditions, the lower the drought index

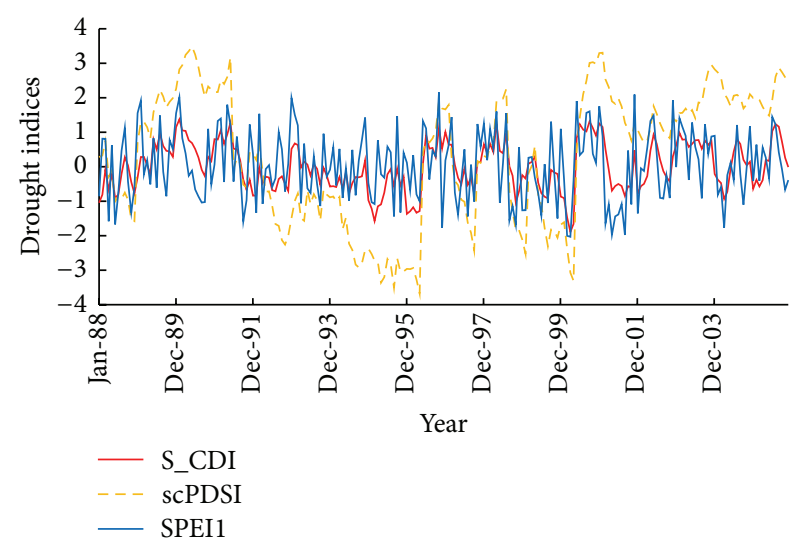

FIgURE 3: Temporal variations of the short-term CDI and its components.

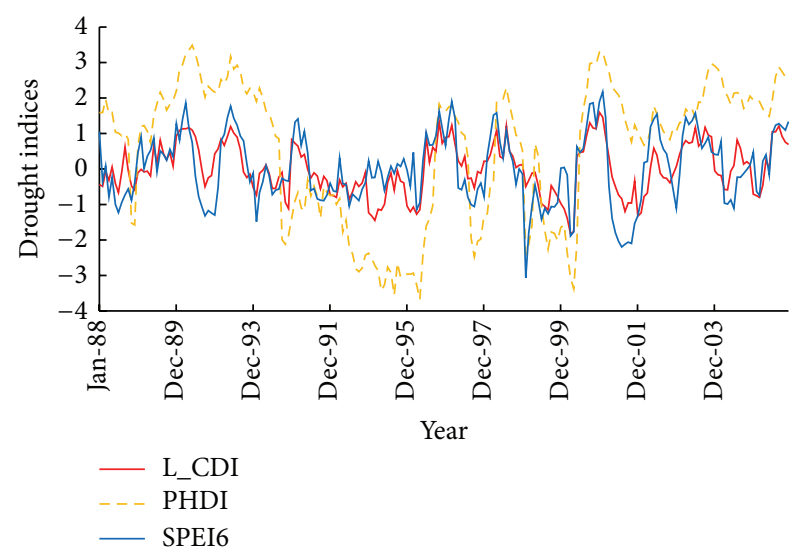

FIgURE 4: Temporal variations of the long-term CDI and its components.

values and the basin was in relatively dry condition in 1990s and early 2000s. Similar variation trends were also found in the L_CDI and the PHDI and the L_CDI and the 6-month SPEI time series (Figure 4). 


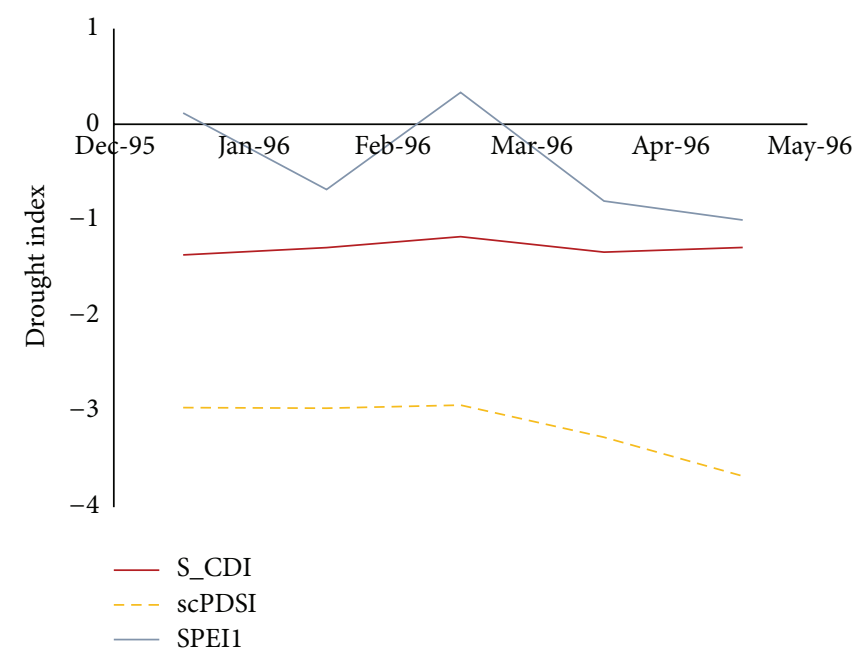

(a) S_CDI

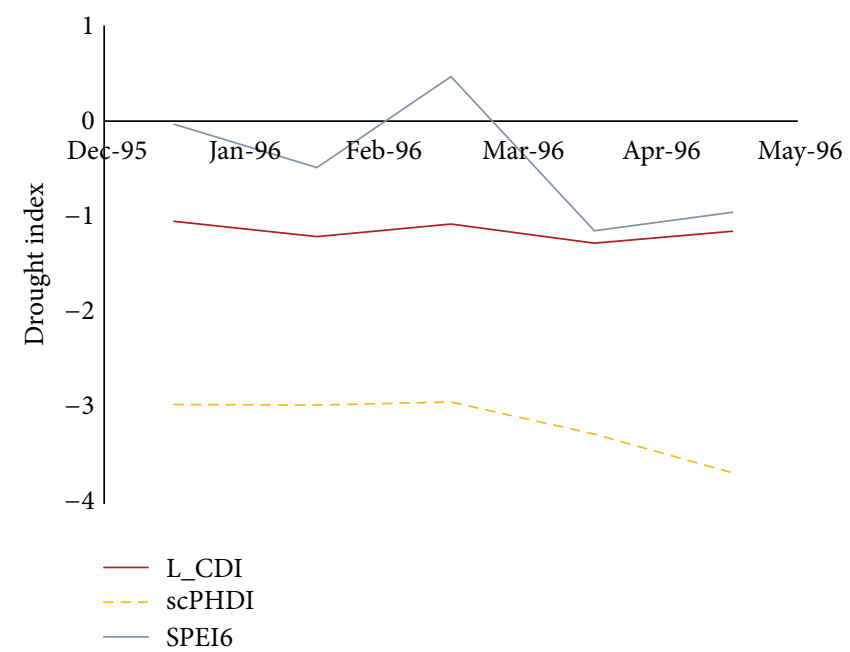

(b) L_CDI

Figure 5: The 1996 drought.

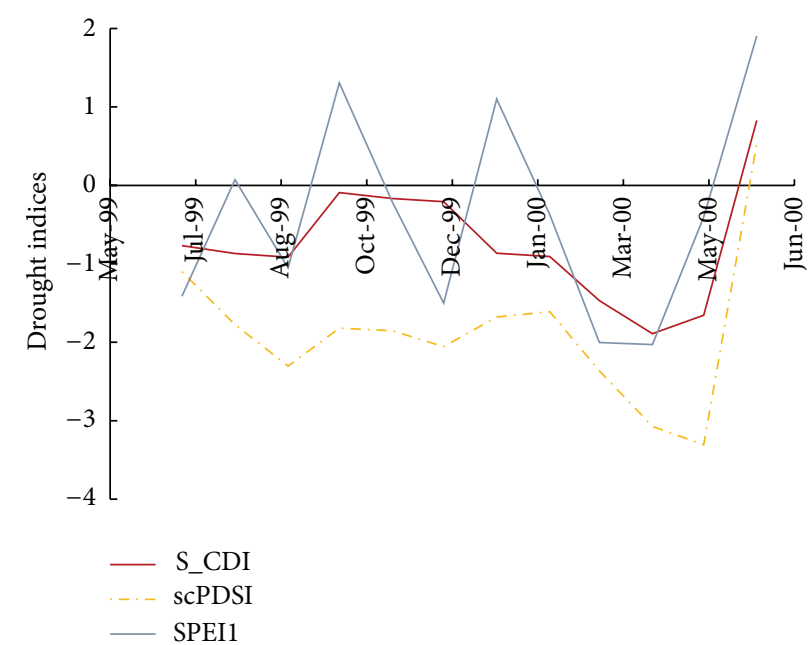

(a) S_CDI

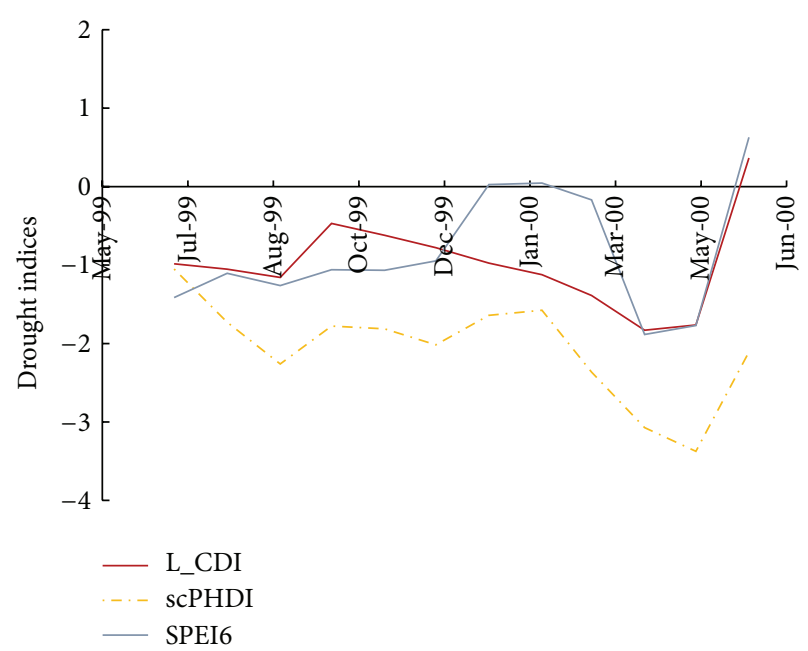

(b) L_CDI

FIgURE 6: The 2000 drought.

Correlations between the CDI and scPDSI/SPEI time series were also investigated by the Spearman correlation coefficient, which is the application of the Pearson correlation coefficient performed upon data ranks instead of the data themselves (e.g., Wilks., [20]), with the range of the Spearman coefficient being constrained within \pm 1 . Rank correlation is a robust measure that is insensitive to the underlying data distribution and is recognized as a competent tool for determining the best aggregate correlation (Wilks, [20]).

Rank correlation between the S_CDI and scPDSI/1month SPEI was found to behave similarly to that between the L_CDI and PHDI/6-month SPEI, that is, Spearman correlation coefficients being of $0.83,0.72$, respectively, between the S_CDI and the scPDSI, and the S_CDI and the 1-month SPEI time series, and Spearman correlation coefficients being of $0.75,0.82$, respectively, between the L_CDI and the PHDI, and the L_CDI and the 6-month SPEI time series.

The variation trends of all the drought indices are consistent with each other; however, the drought severity, onset, and termination identified by different drought indices varied differently.

4.2. Drought Assessment of Critical Drought Events. Two critical drought events - the long-term 2000 drought and the short-term 1996 drought-were used to assess the fidelity of the S_CDI, the L_CDI, and their drought components.

4.2.1. Historical Records of Critical Droughts. The 2000 drought, which actually began from September of 1999 and developed to the severe spring and early summer drought 


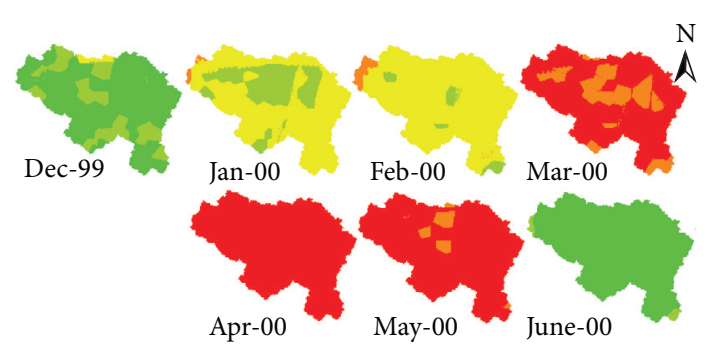

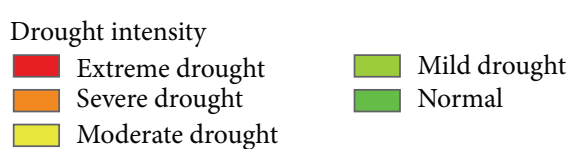

(a) S_CDI

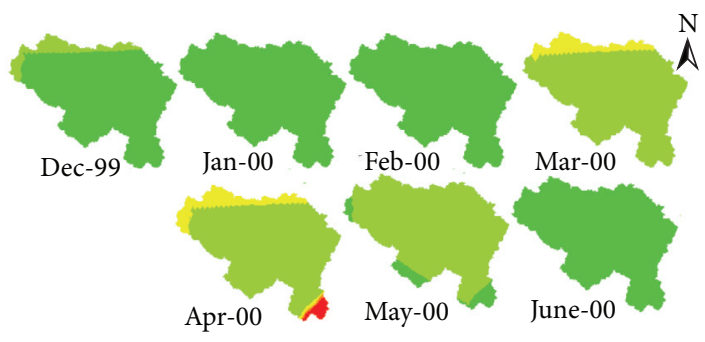

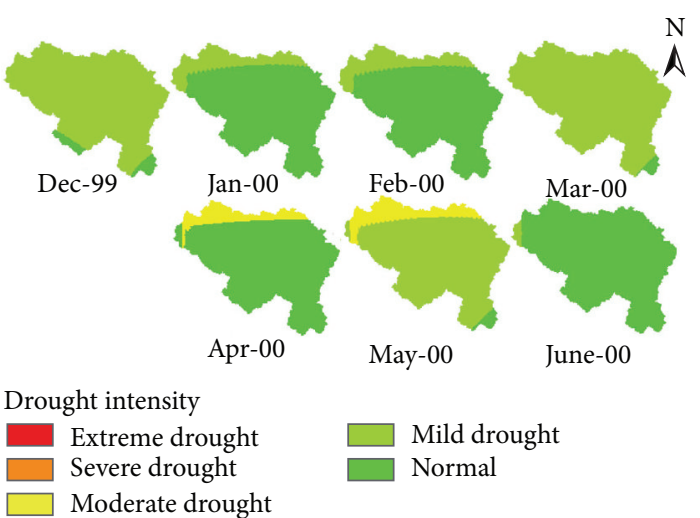

(b) sc_PDSI

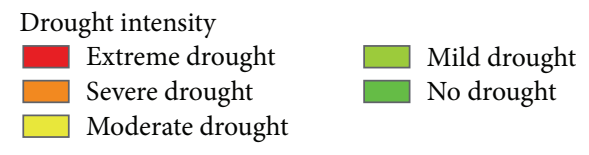

(c) ZIND

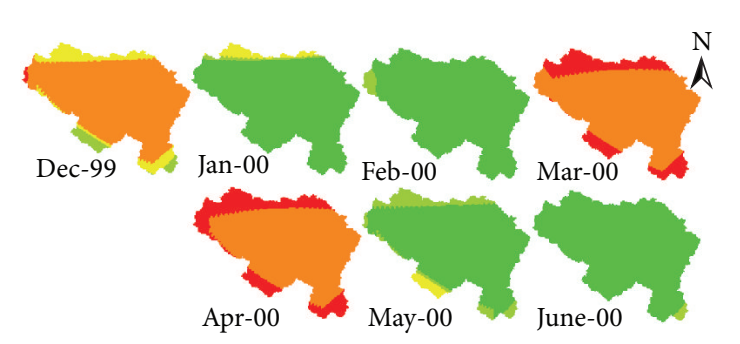

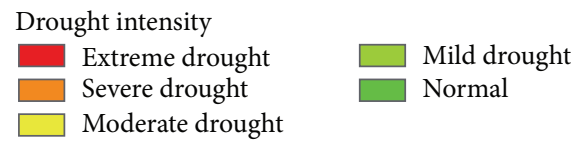

(d) SPEI1

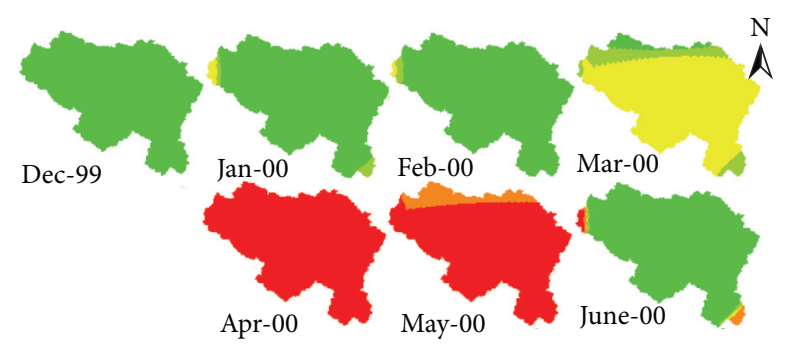

Drought intensity
Extreme drought
$\square$ Severe drought
$\square$ Moderate drought

(e) SPEI3
Mild drought

No drought

FIgURE 7: Dynamic spatial distributions of the S_CDI and its components in the upper Huaihe River basin.

in 2000, was one of the most famous extreme droughts in the Huaihe River basin in history (Zhang, [21]). During this drought, the total precipitation during January-May of 2000 was less than 45 percent of normal, no flow in the main river during April and May. According to incomplete statistics, the precipitation in Shangdong province-one of the major provinces in the Huaihe River basin-decreased 84 percent of normal during March and April, and 50\% large and middle-sized reservoirs in the Province were operated under dead storage level and all the small reservoirs were depleted. The extreme drought in 1996 was also chosen to assess the feasibility of the newly developed CDI. Fortunately this drought event only persisted for a short period.

4.2.2. Drought in 1996. From Figure 5(a), it can be found that severe and extreme droughts in early 1996 were identified by the S_CDI, while only moderate and severe droughts were identified by the scPDSI and no drought by the 1-month SPEI. From Figure 5(b), only moderate and severe droughts were recognized by the L_CDI and the PHDI, and mild drought by the 6-month SPEI. Compared with the historical records, it can be concluded that the S_CDI best described the actual 


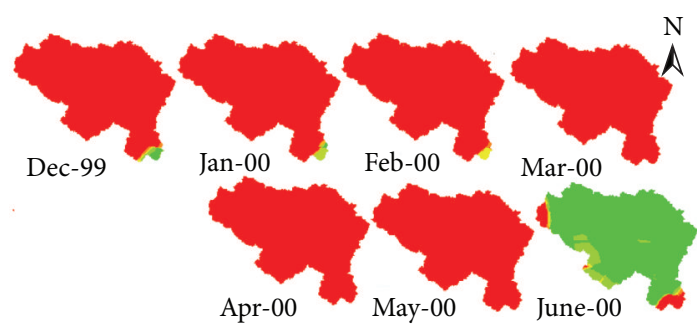

Drought intensity

Extreme drought

Severe drought

Moderate drought

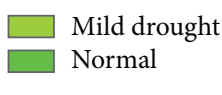

(a) L_CDI

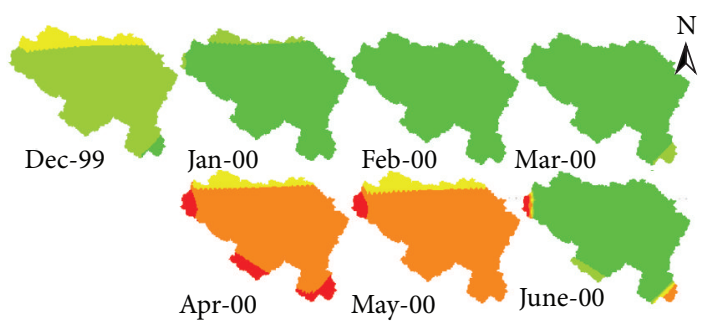

Drought intensity

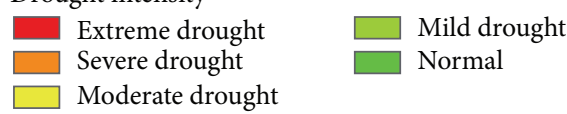

(c) SPEI6

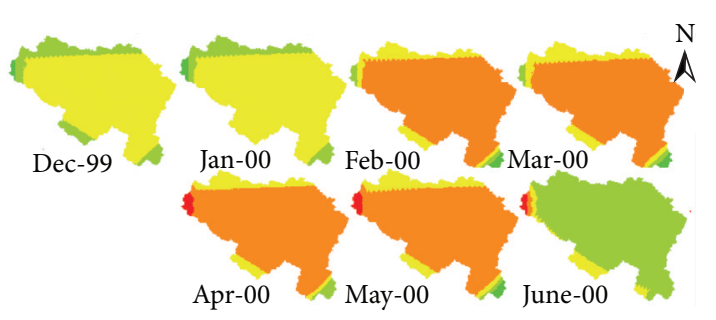

Drought intensity
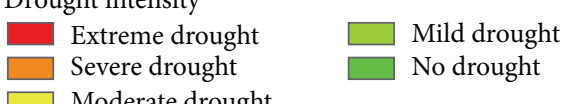

(e) SPEI18

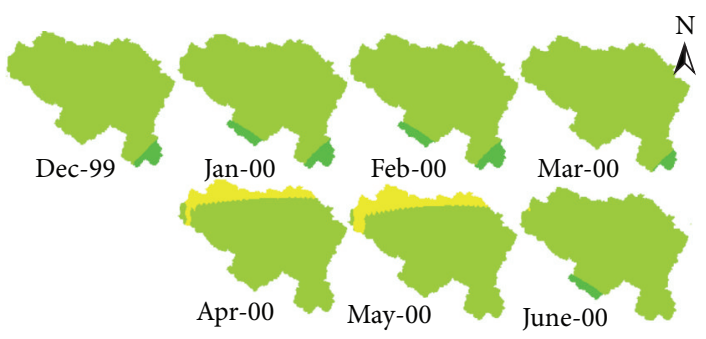

Drought intensity

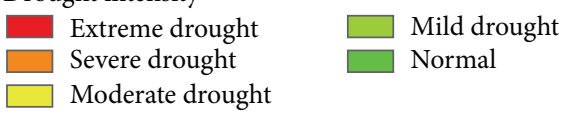

(b) PHDI

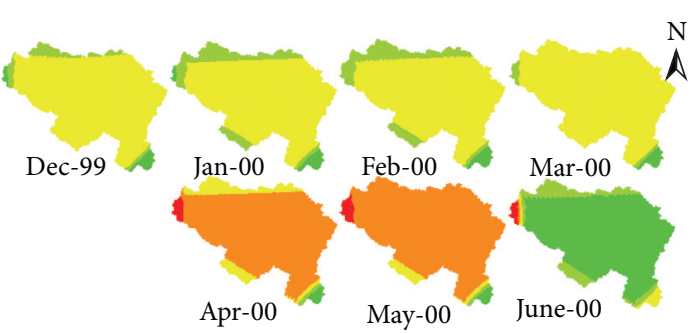

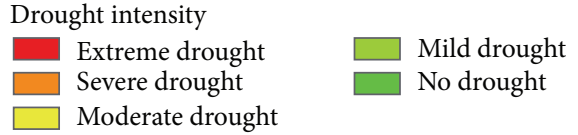

(d) SPEI12

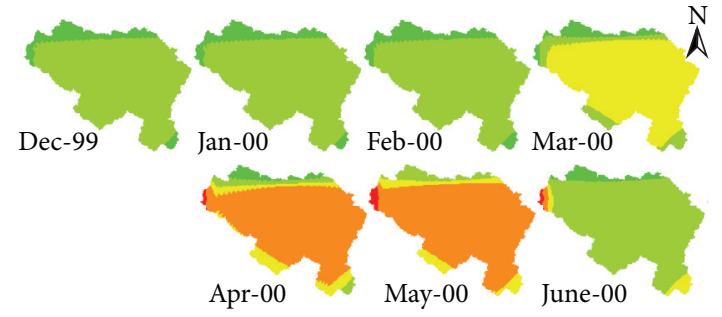

Drought intensity

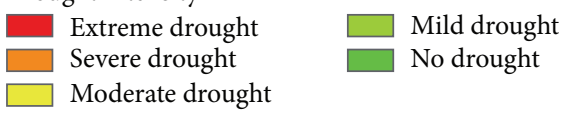

(f) SPEI24
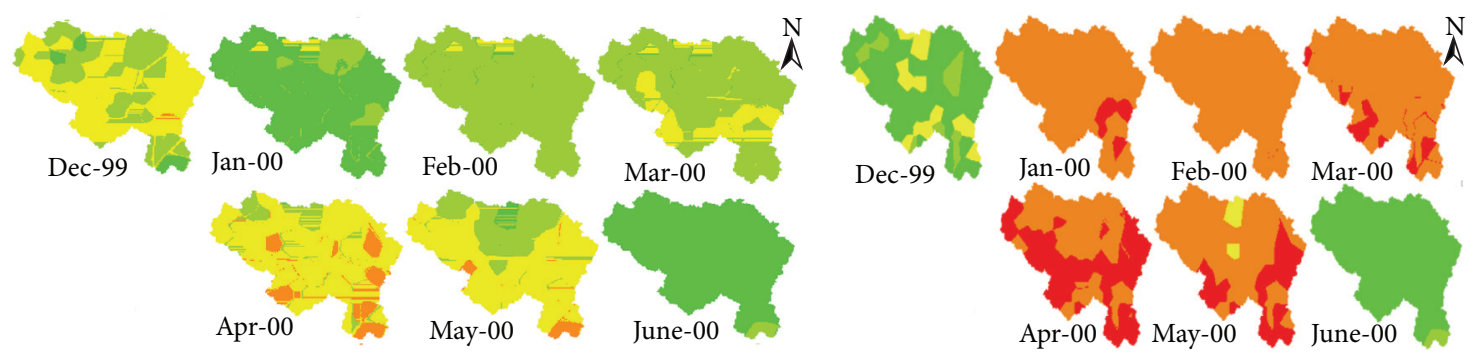

Drought intensity

Extreme drought

$\square$ Severe drought

Moderate drought

Mild drought

No drought

(g) SSI
Drought intensity

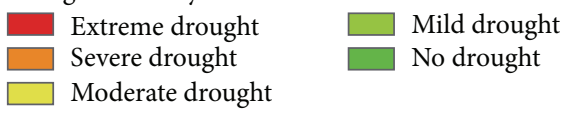

(h) SMI

Figure 8: Dynamic spatial distributions of the L_CDI and its components in the upper Huaihe River basin. 
dry condition of the short-term drought event in 1996. It indicated that the S_CDI could well capture the relative timely dynamic variation of the short-term drought evolution.

4.2.3. Drought in 2000. Both the S_CDI and the 1-month SPEI identified extreme droughts in March and April of 2000. However, the extreme drought continued developing till May of 2000 and it was only detected by the S_CDI, while no drought was found by the 1-month SPEI (Figure 6(a)). In the meanwhile, severe drought was detected by the scPDSI. From Figure 6(b), the L_CDI identified extreme droughts in March-May of 2000 while the 6-month SPEI identified this extreme drought only in April and May. Moreover, moderate drought was also detected from November of 1999 to January of 2000 by the L_CDI, while almost no drought occurred identified by the 6-month SPEI. Severe drought was detected by the PHDI only in April and May. The above comparison demonstrated that the S_CDI and L_CDI best characterized the extreme drought in 2000. Since this drought persisted a relatively long time period, the L_CDI was better identifying the whole drought evolution since the L_CDI detected the severe drought in September of 1999 while the S_CDI did not judge accurately.

4.3. Dynamic Spatial Distributions of Typical Drought Events. Dynamic spatial distributions of the S_CDI and its components in the upper Huaihe River basin were presented in Figure 7. A small part of the basin was firstly found in extreme drought in January 2000 by SMI with the rest in severe drought, while the 1-month SPEI identified the boundary area in extreme drought condition in March 2000 with the rest in severe drought condition. No extreme drought was found by the 3-month SPEI until April and May 2000. The S_CDI discovered moderate drought in January and February 2000, and most part was discovered in extreme drought in March 2000, almost all basin in extreme drought in April and May 2000, and no drought in June 2000. The scPDSI and the ZIND only identified mild drought over the whole period. In general, the S_CDI performed better than any other drought components; however, it was not the best choice while in comparison with the historical records of the 2000 drought. Figure 8 showed dynamic spatial distributions of the L_CDI and its components in the upper Huaihe River basin. Almost the whole upper Huaihe River basin was in extreme drought condition in December 1999 by the L_CDI, and such drought condition continued to May 2000, and the dry condition relieved in June 2000. The SPEI with different time scales only discovered severe drought during the period, and moderate drought was discovered by SSI and only mild drought by PHDI. Comparing Figures 7 and 8 , it can be concluded that the L_CDI best described the drought process, including the drought onset, severity, and termination month.

\section{Conclusions}

The short-term/long-term CDI were developed and applied in the upper Huaihe River basin. The performance of the short-term/long-term CDI was compared with their drought index components and historical records, respectively. The result revealed that the newly built short-term CDI could better capture the drought severity, onset, and termination than the scPDSI and the 1-month SPEI for relatively shortterm droughts, while the long-term CDI behaved better than the PHDI and the 6-month SPEI on drought persistence and magnitude for relatively long-term droughts; the S_CDI is better at drought assessment of short-term drought events while the L_CDI is better at drought assessment of long-term drought events; to obtain a more comprehensive and accurate result during drought assessment, the S_CDI is suggested to be adopted for drought assessment during drought initial period while the L_CDI is used after the drought persisting for a relatively long time period. The output of the paper could provide valuable references for drought estimation and monitoring of other river basins/regions in China.

\section{Conflict of Interests}

The authors declare that there is no conflict of interests regarding the publication of this paper.

\section{Acknowledgments}

Financial support is gratefully acknowledged from the National Science Foundation Commission under Grant no. 41171220, China, and the project (2014B04314) supported by the Fundamental Research Funds for the Central Universities.

\section{References}

[1] Z. C. Hao and A. Aghakouchak, "A nonparametric multivariate multi-index drought monitoring framework," Journal of Hydrometeorology, vol. 15, no. 1, pp. 89-101, 2014.

[2] M.X. Yu, Development and application of the composited drought index [Ph.D. thesis], Hohai University, Nanjing, China, 2013.

[3] M. X. Yu, Q. F. Li, M. J. Hayes, M. D. Svoboda, and R. R. Heim, "Are droughts becoming more frequent or severe in China based on the Standardized Precipitation Evapotranspiration Index: 1951-2010?" International Journal of Climatology, vol. 34, no. 3, pp. 545-558, 2014.

[4] W. Palmer, "Meteorological droughts," Weather Bureau Research Paper, U.S. Department of Commerce, 1965.

[5] N. Wells, S. Goddard, and M. J. Hayes, "A self-calibrating palmer drought severity index," Journal of Climate, vol. 17, no. 12, pp. 2335-2351, 2004.

[6] T. McKee, N. Doesken, and J. Kleist, "The relationship of drought frequency and duration to time scales," in Proceedings of the 8th Conference on Applied Climatology, pp. 179184, American Meteorological Society, Anaheim, Calif, USA, January 1993.

[7] S. M. Vicente-Serrano, S. Beguería, and J. I. López-Moreno, "A multiscalar drought index sensitive to global warming: the Standardized Precipitation Evapotranspiration Index," Journal of Climate, vol. 23, no. 7, pp. 1696-1718, 2010.

[8] S. M. Vicente-Serrano, J. I. López-Moreno, S. Beguería, J. Lorenzo-Lacruz, C. Azorin-Molina, and E. Morán-Tejeda, "Accurate computation of a streamflow drought index," Journal of Hydrologic Engineering, vol. 17, no. 2, pp. 318-332, 2012. 
[9] D. A. Wilhite, Drought and Water Crises: Science, Technology, and Management Issues, Taylor \& Francis, 2005.

[10] W. Xie, S. Wang, W. Tang, R. Wu, and J. Dai, "Comparative analysis on the applicability of drought indexes in the Huaihe River Basin," Journal of Applied Meteorological Science, vol. 25, no. 2, pp. 176-184, 2014.

[11] W. Zhang, Y. Liu, Q. Li, L. Ren, and T. Cai, "Drought evaluation for upper reaches of the Huaihe River," Journal of China Hydrology, vol. 29, no. 5, pp. 69-72, 2009.

[12] R. Zhang, X. Chen, Z. Zhang, and P. Shi, "Evolution of hydrological drought under the regulation of two reservoirs in the headwater basin of the Huaihe River, China," Stochastic Environmental Research and Risk Assessment, vol. 29, no. 2, pp. 487-499, 2015.

[13] W. Zhang, S. Pan, L. Cao et al., "Changes in extreme climate events in eastern China during 1960-2013: a case study of the Huaihe River Basin," Quaternary International, vol. 380-381, pp. 22-34, 2015.

[14] X. Cai, H. Mao, and W. Wang, "Study of the adaptability of multiscale drought indices in Yangtse-Huaihe River basins," Journal of Glaciology and Geocryology, vol. 35, no. 4, pp. 978989, 2013.

[15] Q. Wang, P. Shi, T. Lei et al., "The alleviating trend of drought in the Huang-Huai-Hai Plain of China based on the daily SPEI," International Journal of Climatology, 2015.

[16] K. Duan, W. Xiao, Y. Mei, and D. Liu, "Multi-scale analysis of meteorological drought risks based on a Bayesian interpolation approach in Huai River basin, China," Stochastic Environmental Research and Risk Assessment, vol. 28, no. 8, pp. 1985-1998, 2014.

[17] D.-H. Yan, D.-M. Han, G. Wang, Y. Yuan, Y. Hu, and H.-Y. Fang, "The evolution analysis of flood and drought in Huai River Basin of China based on monthly precipitation characteristics," Natural Hazards, vol. 73, no. 2, pp. 849-858, 2014.

[18] I. T. Jolliffe, Principal Component Analysis, Springer, 2nd edition, 2002.

[19] Z. Ren-Jun, “The Xinanjiang model applied in China," Journal of Hydrology, vol. 135, no. 1-4, pp. 371-381, 1992.

[20] D. S. Wilks, Statistical Methods in the Atmospheric Sciences: An Introduction, vol. 59 of International Geophysics Series, Academic Press, San Diego, Calif, USA, 1995.

[21] S. F. Zhang, Historic Droughts of China 1949-2000, Hohai University Press, Nanjing, China, 2008. 

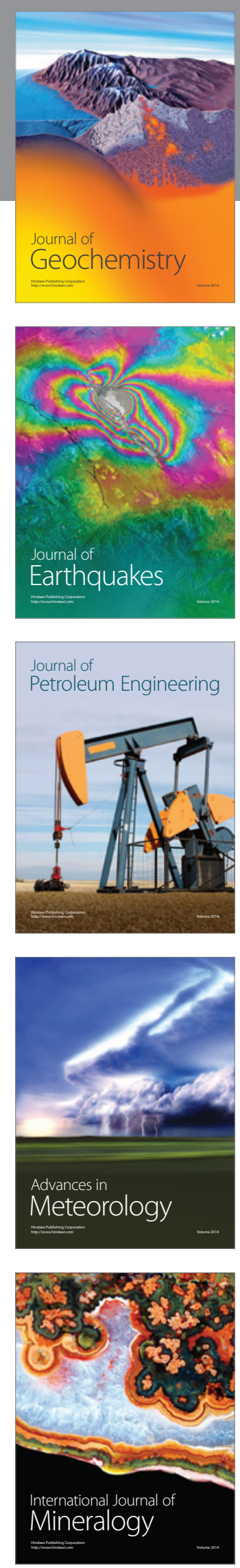
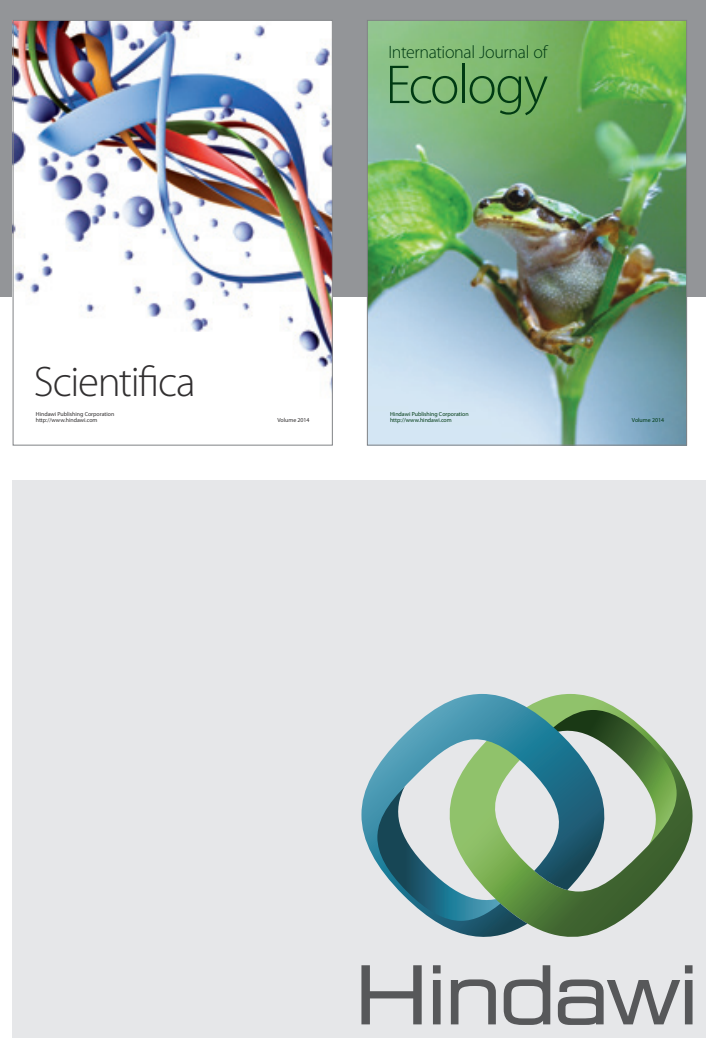

Submit your manuscripts at

http://www.hindawi.com
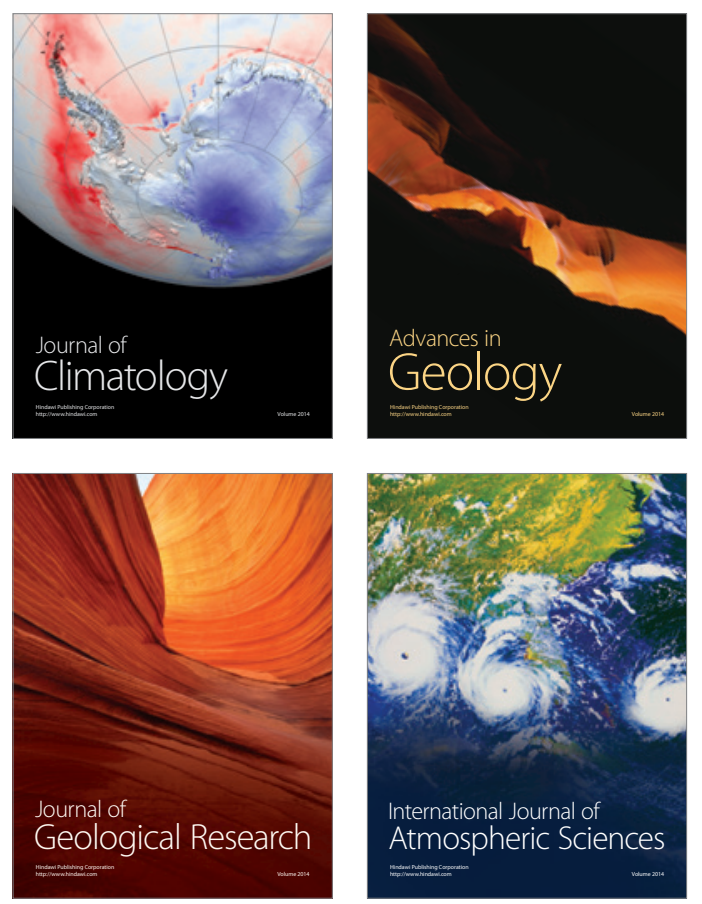

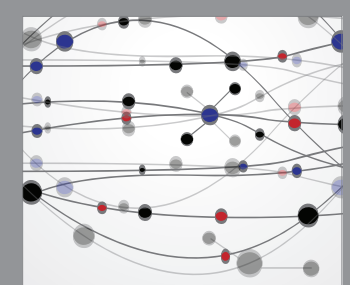

The Scientific

\section{World Journal}
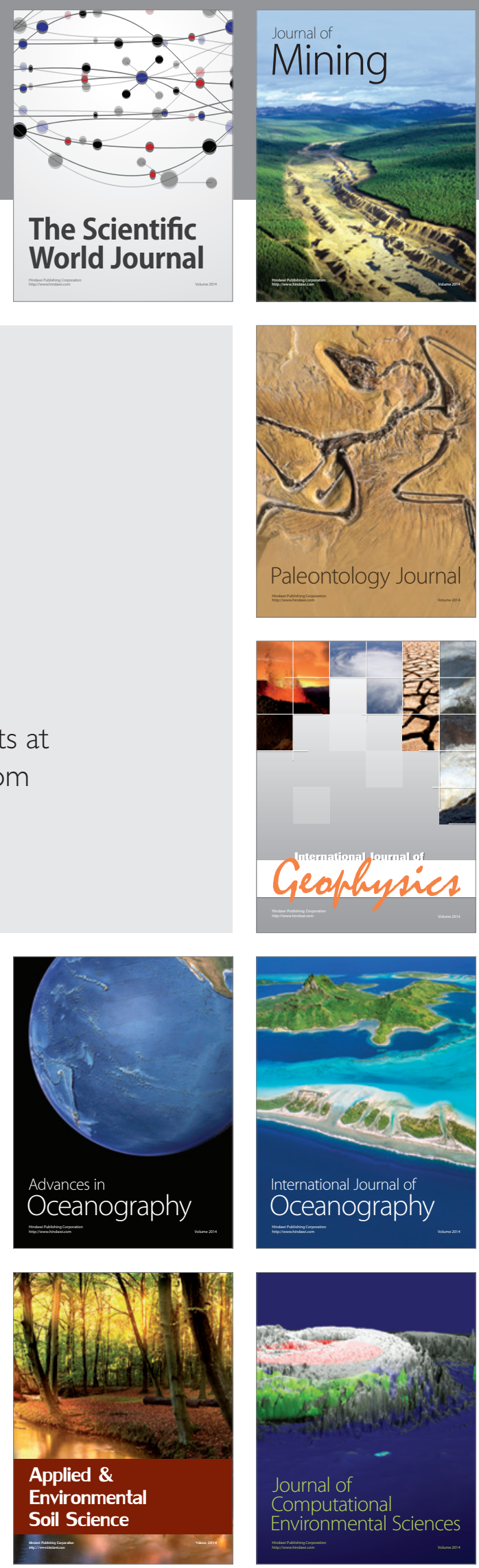